\title{
Experimental study of C-band microwave scattering characteristics during the emulsification process of oil spills
}

\author{
Sijing Shu ${ }^{1,2}$, Junmin Mengl, 2*, Xi Zhang ${ }^{1,2}$, Jie Guo ${ }^{3}$, Genwang Liu ${ }^{1,2}$ \\ ${ }^{1}$ First Institute of Oceanography, Ministry of Natural Resources, Qingdao 266061, China \\ ${ }^{2}$ Ocean Engineering Technology Innovation Center, Ministry of Natural Resources, Qingdao 266061, China \\ ${ }^{3}$ Yantai Institute of Coastal Zone Reaearch, Chinese Academy of Sciences, Yantai 264003, China \\ Received 9 October 2019; accepted 13 January 2020
}

(C) Chinese Society for Oceanography and Springer-Verlag GmbH Germany, part of Springer Nature 2020

\section{Abstract}

In this study, oil spill experiments were performed in a water tank to determine changes in the surface scattering characteristics during the emulsification of oil spills. A C-band fully-polarimetric microwave scatterometer and a vector network analyzer were used to observe films of the following oils: crude oil with an asphalt content below $3 \%$ that is prone to emulsification (type A), fresh crude oil extracted from an oilfield (type B), and industrial crude oil that was dehydrated and purified (type C). The difference in the backscatter results between the emulsified oil film and the calm water surface under C-band microwaves and the influence of the emulsification of the oil film on the backscatter were analyzed in detail. The results demonstrate that under a low-wind and no-waves condition (the maximum wave height was below than $3 \mathrm{~mm}$ ), the emulsification of crude oil could modulated the backscatter through changes in the surface roughness and the dielectric constant, where the surface roughness had the dominant effect. The surface backscatters of the type B oil were greater than that of the type $\mathrm{C}$ oil in both the emulsified and non-emulsified states. In the non-emulsified state, the average differences in the backscatter between the type B and C oils were $2.19 \mathrm{~dB}, 2.63 \mathrm{~dB}$, and $2.21 \mathrm{~dB}$ for the polarization modes of $\mathrm{VV}, \mathrm{HH}$, and $\mathrm{HV} / \mathrm{VH}$, respectively. Smaller corresponding average differences of $0.98 \mathrm{~dB}, 1.49 \mathrm{~dB}$, and $1.5 \mathrm{~dB}$ were found for the emulsified state with a $20 \%$ moisture constant for the oil film. The results demonstrated that the surface roughness of the different oil films could vary due to the differences in the oil compositions and the oil film properties, which in turn affect the backscatter of the oil film surface.

Key words: microwave scattering characteristics of oil spill, emulsification of crude oil, experiment of oil spill, backscatter

Citation: Shu Sijing, Meng Junmin, Zhang Xi, Guo Jie, Liu Genwang. 2020. Experimental study of C-band microwave scattering characteristics during the emulsification process of oil spills. Acta Oceanologica Sinica, 39(7): 135-145, doi: 10.1007/s13131-020-1612-4

\section{Introduction}

The ocean is a strategic resource for human survival and sustainable development. However, the rapid development of industries such as maritime transport and oil extraction has dramatically increased the risk of pollution from oil spills. In the past 30 years, there have been over 60 major oil spill accidents worldwide, creating more than $45 \times 10^{6} \mathrm{~m}^{2}$ of polluted area (Leifer et al., 2012; Fingas and Brown, 2014). These oil spill accidents have seriously damaged the ecological environment of the ocean and caused significant economic losses. Moreover, ocean oil spill pollution often affects a large area, is long lasting, and causes great damage to marine wildlife. The surveillance and monitoring of oil spills have thus attracted considerable attention from marine management departments in many countries (Cai et al., 2016; Zou et al., 2016).

Remote sensing technology is an important method used to monitor and track oil spills. Microwave remote sensing, especially synthetic aperture radar (SAR), can collect data during the day and night and in all weather conditions. SAR is not affected by either clouds or light and produces high-resolution two-dimensional images (Brekke and Solberg, 2005; Fingas and Brown, 1997; Girard-Ardhuin et al., 2005). This technique has been widely applied to ocean oil spill monitoring. SAR can detect oil spills on the sea surface because the Marangoni effect produced by oil films on the sea surface inhibits the formation of shortscale waves or capillary waves in the ocean (Alpers and Hühnerfuss, 1988; Skrunes et al., 2016). The resulting weaker radar echo intensity creates dark areas in radar images that indicate the sea areas covered by the oil film (Fingas and Brown, 1997 ; Zheng et al., 2017). To date, scholars in many countries have carried out extensive research on SAR oil spill detection. These studies have focused on the oil spills detection and discrimination between oil spills and lookalikes. Oil film detection has largely been based on detecting dark spots in images. Gemme and Dellepiane (2018) proposed an automatic, unsupervised method to detect sea surface oil spills and extract spill information. Topouzelis et al. $(2007,2008)$ and Del Frate et al. ( 2000) applied neural networks to high-resolution SAR satellite images to detect oil spills. Solberg et al. ( 2003) designed a classifier for oil spill detection, defined 10 characteristics, and applied Bayesian theory to discriminate oil spills from lookalikes. Chehresa et al.(2016) proposed an algorithm for selecting the optimal features from SAR images to distinguish oil spills from lookalikes . Nunziata and Migliaccio successfully detected ocean oil spills and distin-

Foundation item: The National Key R\&D Program of China under contract No. 2016YFC1401000; The National Natural Science Foundation of China under contract Nos 41576032 and 41706208.

*Corresponding author, E-mail: mengjm@fio.org.cn 
guished oil spills from biological oil films using co-polarized phase differences (Migliaccio et al., 2009).

The increasing demand for oil spill monitoring has made it necessary to not only accurately detect and locate oil spills but also obtain key information about the oil spill, such as the type, thickness, and state, which are of considerable significance for the response and subsequent cleanup of oil spill accidents. Thus, it is essential to study the properties of oil spills, including dielectric properties and microwave scattering characteristics. It is not sufficient to analyze only the grayscale and texture characteristics of oil spill areas in radar images. In recent years, scholars in many countries have used microwave equipment to carry out various types of oil spill experiments, which are mainly divided into indoor and outdoor experiments (Guo et al., 2016). Outdoor experiments refer to the intentional pouring of oil into natural marine environments to simulate the occurrence of an oil spill and the monitoring of the spill through satellite-borne (Skrunes et al., 2014, 2016), airborne (Angelliaume et al., 2018; Ulaby et al., 1986), land-based, and ship-based equipment (Wismann et al., 1998). This method offers the advantage of simulating the real environment but is difficult to implement, is costly, and causes environmental pollution. Therefore, scholars are currently more inclined to carry out indoor experiments by building wind-wave tanks. Regarding the experimental aspect of distinguishing types of oil spill, in 1992, Alpers et al. (1988) built a $26.0 \mathrm{~m} \times 1.0 \mathrm{~m} \times 0.5 \mathrm{~m}$ indoor wind-wave tank, using two types of oil, namely, light fuel oil and heavy fuel oil, and carried out the experiments using scatterometers with L-, S-, C-, and X-bands (Gade et al., 1998). Yang et al. (1993) studied oil film thickness inversion in 1987 by using a microwave radiometer to analyze the relationship between the thickness and brightness temperature of an oil film. Pang and Sun (2003) used a microwave radiometer to analyze the relationship between microwave radiation and the film thicknesses of petroleum, fuel oil, and edible oil. Loor et al. (1978) studied multimethod oil spill detection in 1971 by launching a remote sensing ocean monitoring plan and building $100.0 \mathrm{~m} \times 8.0 \mathrm{~m} \times 0.5 \mathrm{~m}$ indoor wind-wave tanks to simulate a marine environment. The microwave scattering characteristics of ocean wind waves and oil spills were analyzed by using airborne side vision radar and infrared sensor detection equipment.

Numerous indoor and outdoor spill experiments have been carried out, but the effect of changes in the oil film properties on the film surface scattering characteristics, especially the effect of the emulsification of oil spills on microwave scattering, have not been considered. However, the emulsification caused by wave action and weathering will not only increases the viscosity, surface tension, and volume of oil film (Fingas, 1995; Khan et al., 2011) but also cause the oil to mix with seawater and form a water-in-oil emulsion (Thingstad and Pengerud, 1983). The considerable modification of the nature of the oil, and the emulsification state and properties of the oil film change continuously over a period of hours to days (Minchew et al., 2012). The resulting water-in-oil emulsion exhibits characteristics between those of a liquid and a solid with a loose and porous surface (Fingas and Fieldhouse, 2003, 2004; Fingas, 1995).

Therefore, it is not known whether the emulsification state change affects the microwave scattering characteristics or the detection accuracy for oil spill. In this study, oil spill experiments were performed in an outdoor water tank. Different types of oil were used with a C-band fully-polarimetric microwave scatterometer ( $\mathrm{HH}, \mathrm{VV}, \mathrm{HV}$, and $\mathrm{VH})$ and a vector network analyzer to analyze the changes in the microwave scattering characteristics in the emulsification of oil spills. The differences in the emulsific- ation-induced microwave scattering among different types of oil were also investigated.

This paper is organized as follows. In Section 1, background information and the goal of the study are presented. The experimental setup, data collection, and meteorological conditions during the experiment are presented in Section 2. The experimental results and analysis are given in Section 3, and conclusions are drawn in Section 4.

\section{Experiment setup and data collection}

The experimental site was located at the Muping Coastal Environment Research Station of the Chinese Academy of Science. The experiment consisted of two stages. The first stage lasted for $5 \mathrm{~d}$ from August 23 to August 27, 2017, and the second stage lasted for $4 \mathrm{~d}$ from September 15 to September 18, 2018. The experiments were performed in the same fiberglass tank (length $\times$ width $\times$ depth, $6.0 \mathrm{~m} \times 2.2 \mathrm{~m} \times 0.7 \mathrm{~m}$ ). Three types of crude oil were tested: crude oil with an asphalt content below $3 \%$ that was prone to emulsification (type A), fresh crude oil extracted from an oilfield (type B), and industrial crude oil that was dehydrated and purified (type $\mathrm{C}$ ). The parameters of the oils are given in Table 1 . The main measuring equipment included a fully-polarimetric C-band microwave scatterometer and a vector network analyzer. Figure 1 shows the experimental setup. The microwave scatterometer was mounted on a platform at the narrow end of the tank. Before the experiments were performed, the tank was filled to a depth of $0.35 \mathrm{~m}$ with seawater with a density of $1.02 \mathrm{~g} / \mathrm{mL}$.

In the first stage of experiment, the emulsification of one type of oil and the impact of the amount of oil on the backscatter of the oil film was mainly investigated. Type A crude oil was used throughout this stage. The oil was added to the tank in eight increments to reach a cumulative amount of $6996.7 \mathrm{~g}$. To simulate the stirring effect of waves on an oil film in a natural marine environment, the oil film was stirred artificially after each increment and then measured with the scatterometer after the water surface calmed down. The stirring times and scatterometer measurements are shown in Fig. 2.

In the second stage of experiment, the effect of the emulsification of different types of oil on the backscatter was mainly stud-

Table 1. Parameters of the three types of crude oil used in experiments

\begin{tabular}{cccc}
\hline Parameter & Type A/\% & Type B/\% & Type C/\% \\
\hline Asphalt content & 1.35 & 7.50 & $>7$ \\
Moisture constant & 0.64 & 7.76 & 0 \\
\hline
\end{tabular}

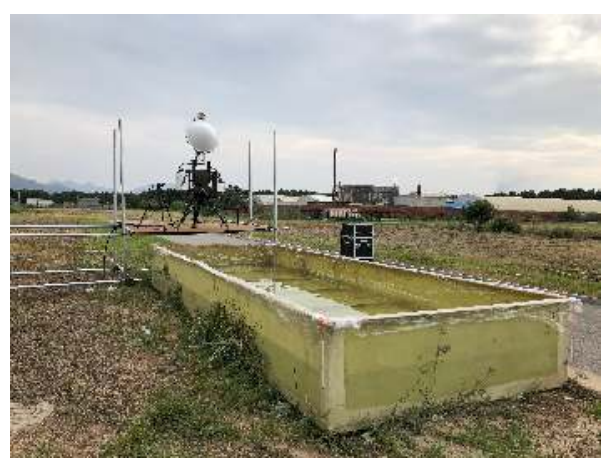

Fig. 1. Experimental setup: the microwave scatterometer was mounted on a platform at the narrow end of the tank, and the walls of the tank were wrapped with cling film to prevent attachment by the oil film. 
ied, and the differences in the backscatter between oil types for different emulsification states were analyzed. Type $B$ and $C$ crude oils were used in this stage. The crude oil emulsification process was simulated using oil samples with moisture constants of $0 \%$, $10 \%, 20 \%$, and $30 \%$ and $0 \%, 20 \%, 40 \%$, and $50 \%$ for type B and C oils, respectively. The moisture constant is an important indicator of the emulsification state of an oil spill and can be calculated as follows:

$$
W_{\mathrm{c}}=\frac{m_{\mathrm{water}}}{m_{\mathrm{oil}}+m_{\mathrm{water}}} \times 100 \%,
$$

where $m_{\text {water }}$ is the mass of water, and $m_{\text {oil }}$ is the mass of oil. A water-in-oil emulsion was prepared as follows. A mixed solution of the desired ratio of crude oil to seawater was added to a JJ-2A mixer and mixed at a rate of $600 \mathrm{r} / \mathrm{min}$. After stirring, the solution was allowed to rest for $24 \mathrm{~h}$. If water accumulated at the bot- tom of the container, the solution was mixed again until all of the water was incorporated. After the scatterometer measurement for each oil sample was completed, the tank was treated to remove any oil residue. The detailed cleaning process and verification are given in Appendix A. The specific experimental procedure and amounts of oil added are given in Fig. 2. The entire experimental process was recorded by a high-resolution video camera to document the diffusion and distribution of the oil film.

\subsection{Meteorological conditions}

Wind and hydrological data were also recorded throughout the experiments. The wind information was obtained from a small weather station $200 \mathrm{~m}$ from the water tank (the measurement frequency was every half hour). As shown in Fig. 3, the wind speed was low during the experiments. The average wind speed was $3.8 \mathrm{~m} / \mathrm{s}$ during the first experimental stage and $2.6 \mathrm{~m} / \mathrm{s}$ during the second stage. Protected by the walls of the water tank and

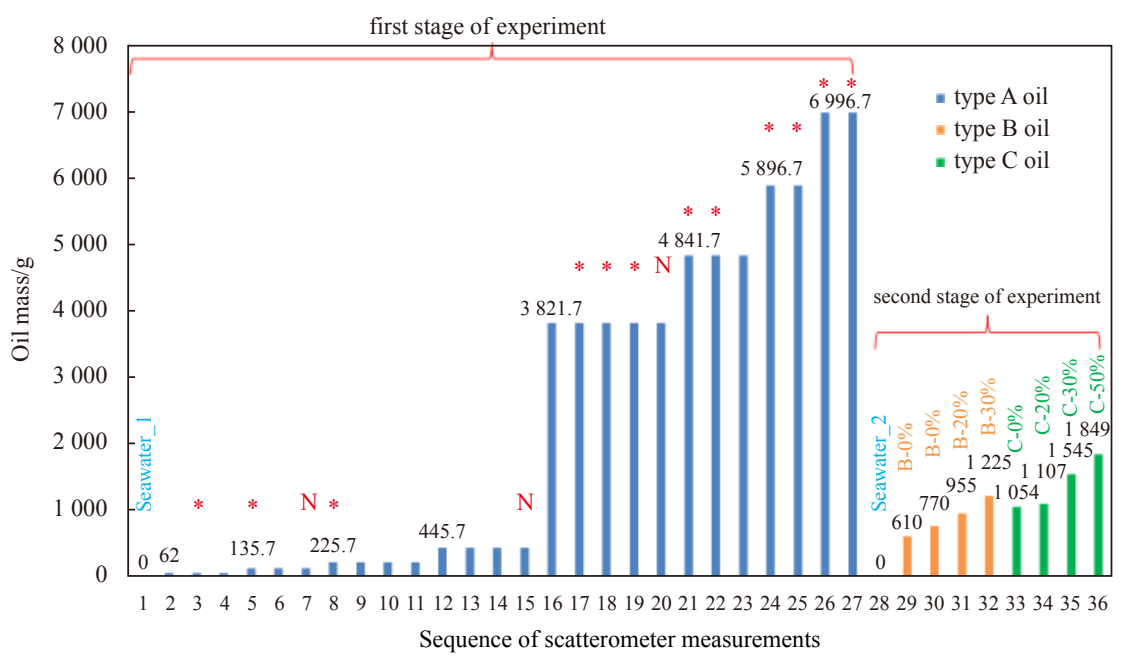

Fig. 2. Diagram of the experimental procedure. The column length indicates the amount of oil added. The different colors represent the different types of crude oil tested. The abscissa indicates the order of the scatterometer measurements, and the corresponding time is shown in Table 2. The symbol "*" indicates that the oil sample was artificially stirred. N indicates that the oil film was allowed to rest overnight, and "B-0\%" denotes type B oil with a moisture constant of $0 \%$.

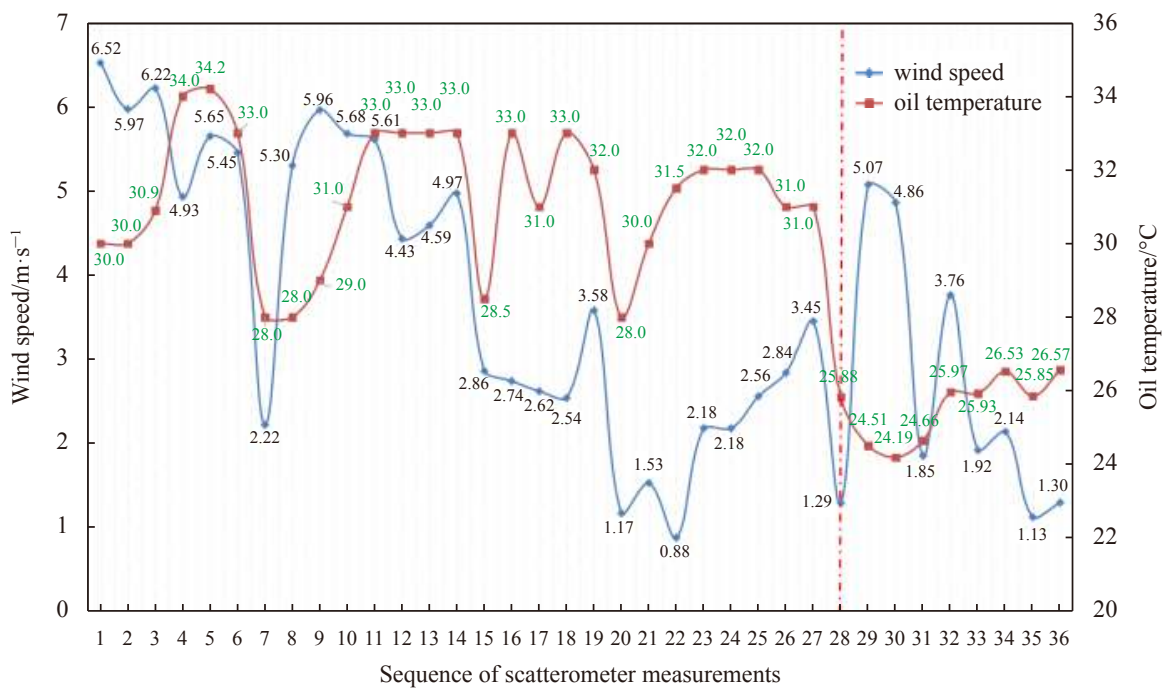

Fig. 3. Wind speed and oil film temperature: the wind speed data were derived from averaging the measurements collected by a small weather station every $30 \mathrm{~m}$. The oil film temperature data were collected by thermometers. See Table 2 for the corresponding times of the sequences on the horizontal axes. 
Table 2. Sequence of scatterometer measurements and corresponding time in the two experimental stages

\begin{tabular}{|c|c|c|c|c|c|c|c|}
\hline \multicolumn{6}{|c|}{ First stage of experiment } & \multicolumn{2}{|c|}{ Second stage of experiment } \\
\hline 1 & $2017-08-24$ 10:03 & 10 & $2017-08-2513: 35$ & 19 & $2017-08-2616: 33$ & 28 & 2018-09-15 08:44 \\
\hline 2 & 2017-08-24 10:20 & 11 & 2017-08-25 14:05 & 20 & $2017-08-27$ 07:55 & 29 & 2018-09-16 14:25 \\
\hline 3 & 2017-08-24 11:09 & 12 & $2017-08-2515: 28$ & 21 & 2017-08-27 10:09 & 30 & 2018-09-16 16:41 \\
\hline 4 & 2017-08-24 16:03 & 13 & 2017-08-25 15:48 & 22 & 2017-08-27 10:50 & 31 & 2018-09-17 09:01 \\
\hline 5 & $2017-08-24$ 16:36 & 14 & $2017-08-2516: 57$ & 23 & 2017-08-27 11:53 & 32 & 2018-09-17 10:49 \\
\hline 6 & $2017-08-24$ 17:56 & 15 & $2017-08-2608: 10$ & 24 & $2017-08-2714: 26$ & 33 & 2018-09-15 09:18 \\
\hline 7 & 2017-08-25 08:02 & 16 & $2017-08-26$ 10:06 & 25 & 2017-08-27 15:00 & 34 & 2018-09-15 15:09 \\
\hline 8 & 2017-08-25 08:58 & 17 & 2017-08-26 11:12 & 26 & $2017-08-27$ 16:22 & 35 & 2018-09-17 14:32 \\
\hline 9 & 2017-08-25 10:30 & 18 & $2017-08-2613: 48$ & 27 & $2017-08-27$ 17:30 & 36 & 2018-09-15 16:29 \\
\hline
\end{tabular}

the surrounding buildings, the surface of the water in the tank was calm, without observable ripples. In the experiments, the surface wave height was measured by wave gauge. Four Locations are selected on the left and right sides of the scanning area of $40^{\circ}$ incidence angle of scatterometer to measure the surface wave height. As shown in Table 3, the maximum wave height was below $3 \mathrm{~mm}$. Thus, the experiments were carried out in an ideal environment with low wind speed and no waves. Therefore, the wind had a minimum impact on the experiments, and the impact of the emulsification of the oil film on the microwave scattering characteristics could be better analyzed.

Table 3. Wave heights of water surface at different wind speeds $(\mathrm{mm})$

\begin{tabular}{ccccc}
\hline Date & Location 1 & Location 2 & Location 3 & Location 4 \\
\hline 2018-09-14 14:24 & 1.5250 & 2.0494 & 2.7826 & 2.2572 \\
$2018-09-1415: 19$ & 2.1491 & 2.5218 & 2.8413 & 2.8757 \\
2018-09-14 15:32 & 2.8757 & 2.1668 & 2.1578 & 2.0658 \\
2018-09-14 16:43 & 1.9333 & 1.7842 & 2.1054 & 2.9052 \\
2018-09-14 16:52 & 2.8247 & 2.4361 & - & - \\
2018-09-15 08:14 & 1.1515 & 1.3464 & 1.1894 & 0.9226 \\
$2018-09-1508: 25$ & 1.2580 & 1.0042 & 1.1056 & 1.0925 \\
\hline
\end{tabular}

\subsection{Data collection}

\subsubsection{Fully-polarimetric backscatter coefficients}

The fully-polarimetric $\sigma_{\mathrm{VV}}^{0}, \sigma_{\mathrm{HV}}^{0}, \sigma_{\mathrm{VH}}^{0}$, and $\sigma_{\mathrm{HH}}^{0}$ measurements were produced by a C-band microwave scatterometer that could obtain the normalized radar backscatter coefficients of four polarization channels. The scatterometer used in these experiments was designed and produced by the ProSensing Company in the United States (Fig. 1). The antenna diameter of the scatterometer was $D=0.61 \mathrm{~m}$ and functioned in the C-band, which has a wavelength $\lambda=0.055 \mathrm{~m}$. A detailed description of the scatterometer system specifications is provided in Table 4 . The scatterometer was mounted on a $0.9 \mathrm{~m}$ tall platform. Within a $60^{\circ}$ azimuth scan range, the scatterometer scan lines were averaged as a function of the system geometry and antenna beam-width to obtain a minimum of eight independent samples per scan line. Measurements were taken at $5^{\circ}$ intervals between the incident angles of $25^{\circ}$ and $60^{\circ}$ (Fig. 4). The scanning time of each angle was approximately one second. The radar footprint was a circle with a diameter of approximately $0.8 \mathrm{~m}$. To reduce the measurement error, three scans were carried out with the scatterometer for each measurement. After removing the outliers, the mean value of the backscatter was calculated. Given the context of the present study, only the backscatter coefficients $\left(\sigma_{\mathrm{VV}}^{0}, \sigma_{\mathrm{HV} / \mathrm{VH}}^{0}\right.$, and
Table 4. C-band scatterometer specifications

\begin{tabular}{ll}
\hline \multicolumn{1}{c}{ Radar parameter } & \multicolumn{1}{c}{ Value } \\
\hline RF output frequency & $5.25-5.75 \mathrm{GHz}$ \\
Transmit power & $+7 \mathrm{dBm}(5.0 \mathrm{~mW})$ \\
Transmit bandwidth & $500 \mathrm{MHz}$ \\
Range resolution & $0.3 \mathrm{~m}$ (typical) \\
Antenna 6-dB two-way & $10.1^{\circ}$, product of transmit and receive \\
beam width & antenna patterns \\
Cross-polarization isola- & $>30 \mathrm{~dB}$, measured at the peak of the \\
tion & beam \\
Transmit/receive polariz- & linear, vertical and horizontal \\
ations & variable, $0.1-15 \mathrm{~ms}(1 \mathrm{~ms}$ typical $)$ \\
Chirp length & $\begin{array}{l}\text { 14-bit resolution, } 10 \mathrm{MS} / \mathrm{s} \mathrm{raw} \mathrm{sample} \\
\text { 2-channel digitizer }\end{array}$ \\
& rate \\
\hline
\end{tabular}

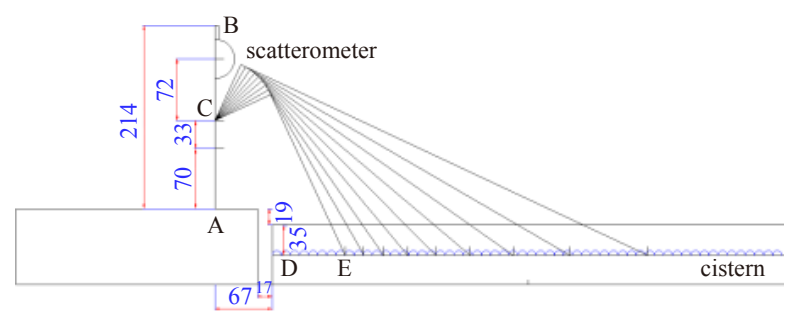

Fig. 4. Diagram showing scatterometer mechanism: labeled lengths have units of $\mathrm{cm}$. The height of the water surface is $35 \mathrm{~cm}$. $\mathrm{AB}$ is the height of the scatterometer, $\mathrm{AC}$ is the height of the scatterometer shaft, and DE is the corresponding position of the $25^{\circ}$ incident angle in the tank.

$\left.\sigma_{\mathrm{HH}}^{0}\right)$ were used, where the cross-polarized backscatter coefficients $\sigma_{\mathrm{HV}}^{0}=\sigma_{\mathrm{VH}}^{0}$.

Table 5 shows that the average distance from the scatterometer to the water surface in the experiments was $2.4 \mathrm{~m}$. This distance is greater than the near-field limit $\left(r_{n}=\lambda / \pi=0.0175 \mathrm{~m}\right)$ and smaller than the far-field limit $\left(r_{f}=2 D^{2} / \lambda=13.53 \mathrm{~m}\right)$. Therefore, it was necessary to conduct a near-field calibration on the measurement results. The calibration was carried out using the builtin system. Details of the calibration process, the near-field correction and error determination are documented in Baldi, (2014).

\subsubsection{Dielectric constant}

An Agilent vector network analyzer (model N1500/85070E) was used to measure the dielectric constant of the oil samples (Fig. 5). The operating frequency of this instrument ranged from $200 \mathrm{MHz}$ to $20 \mathrm{GHz}$, and the dielectric constant measurement accuracy was \pm 0.05 . To ensure measurement accuracy, each oil sample was measured three times to calculate a representative 
Table 5. Corresponding tank positions for different scatterometer scanning footprints at different incident angles

\begin{tabular}{ccccccccc}
\hline Year & $25^{\circ}$ & $30^{\circ}$ & $35^{\circ}$ & $40^{\circ}$ & $45^{\circ}$ & $50^{\circ}$ & $55^{\circ}$ & $60^{\circ}$ \\
\hline 2017 & 92.85 & 114.98 & 140.13 & 169.28 & 203.82 & 245.84 & 298.60 & 367.52 \\
2018 & 85.65 & 106.78 & 130.83 & 158.73 & 191.82 & 232.12 & 282.75 & 348.93 \\
\hline
\end{tabular}

mean dielectric constant. Table 6 shows the measurement results of the relative dielectric constant of the seawater and the type B oil with different moisture constants.

\section{Results and analysis}

\subsection{Analysis of differences in backscatter between emulsified oil films and calm water surface}

In this section, the differences $\left(\Delta=\sigma_{\text {oil }}^{0}-\sigma_{\text {water }}^{0}\right)$ between the backscatter of the type A oil and the seawater surface in the first experimental stage are presented and analyzed. As shown in Fig. 6, most of the measurement results show that the backscatter of the oil film is greater than that of the seawater surface under each polarization mode. The proportions of the experimental samples corresponding to the $\mathrm{VV}, \mathrm{HH}$ and $\mathrm{HV} / \mathrm{VH}$ polarization modes are $71.15 \%, 78.21 \%$, and $64.1 \%$, respectively.

The aforementioned difference in the backscatter is attributed to the change in the surface roughness from crude oil emulsification. As shown in Fig. 7, the produced water-in-oil emulsion exhibited characteristics between those of a liquid and a sol-

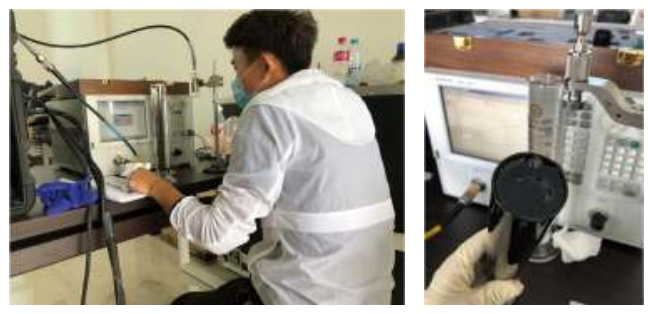

Fig. 5. The dielectric constant was measured by a vector network analyzer. The black fluid in the test tube is the oil sample to be tested.

Table 6. Dielectric constant of seawater and type B oil with different moisture constants

\begin{tabular}{cc}
\hline Sample & C-band (5.34 GHz) \\
\hline seawater & $66.7+33.9 \mathrm{i}$ \\
B-0\% ${ }^{1)}$ & $2.61+0.21 \mathrm{i}$ \\
B-10\% & $3.07+0.04 \mathrm{i}$ \\
B-20\% & $7.31+2.95 \mathrm{i}$ \\
B-30\% & $8.2+1.08 \mathrm{i}$
\end{tabular}

Note: ${ }^{1)}$ B-10\% denotes type B oil with a $10 \%$ moisture constant.
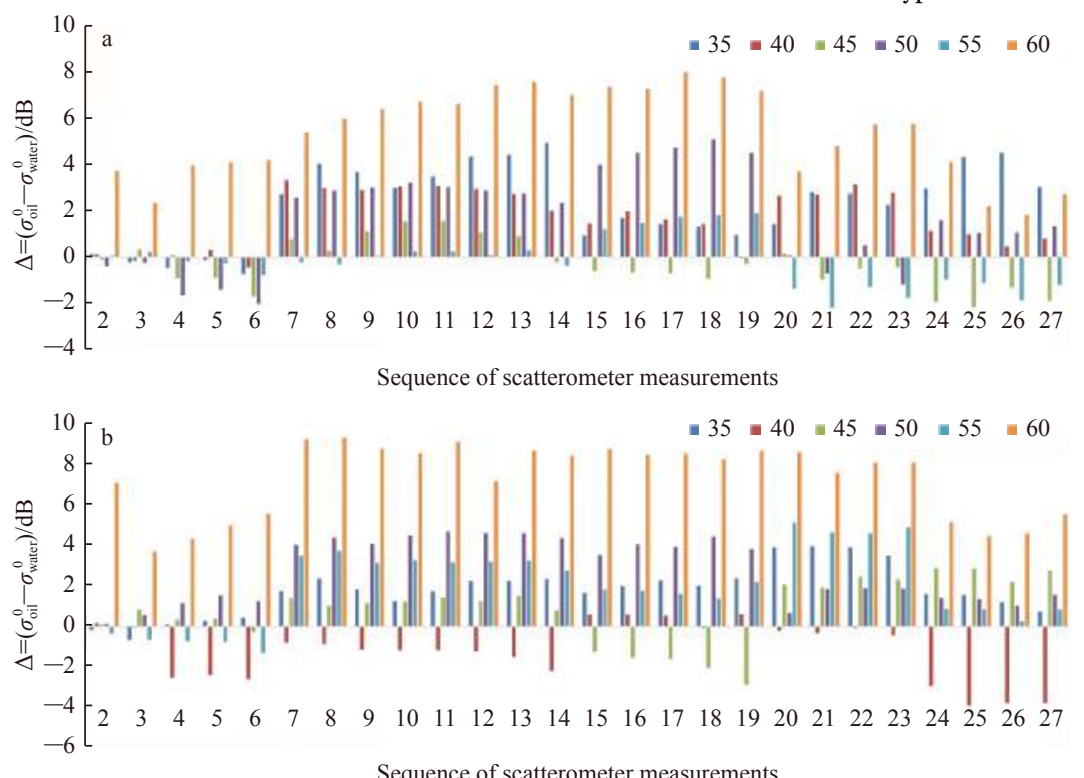

Sequence of scatterometer measurements

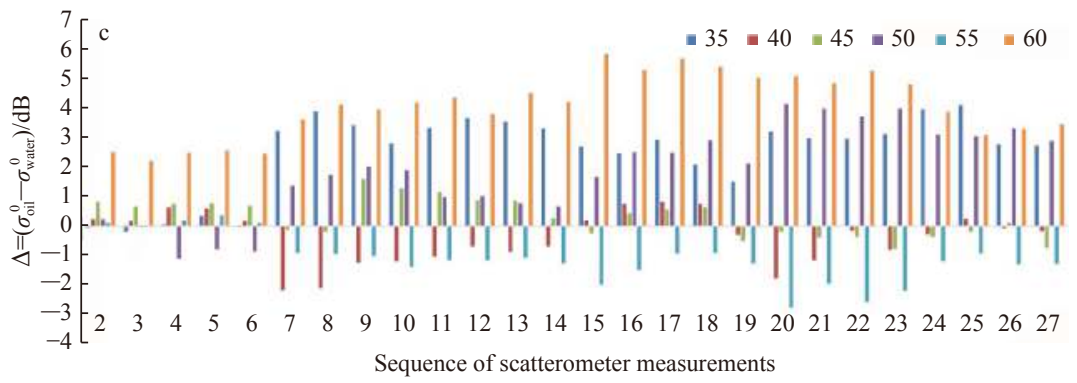

Fig. 6. Backscattering difference between the oil film and seawater surfaces under different polarization modes and different incident angles: $\mathrm{VV}$ (a), HH (b), and HV/VH (c). The ordinate is the difference $\Delta=\left(\sigma_{\text {oil }}^{0}-\sigma_{\text {water }}^{0}\right)$, positive values indicate $\sigma_{\text {oil }}^{0}>\sigma_{\text {water }}^{0}$, abscissa numbers correspond to scatterometer measurements for different cumulative amounts of oil added, and corresponding amounts of oil and times are given in Fig. 2 and Table 2. 

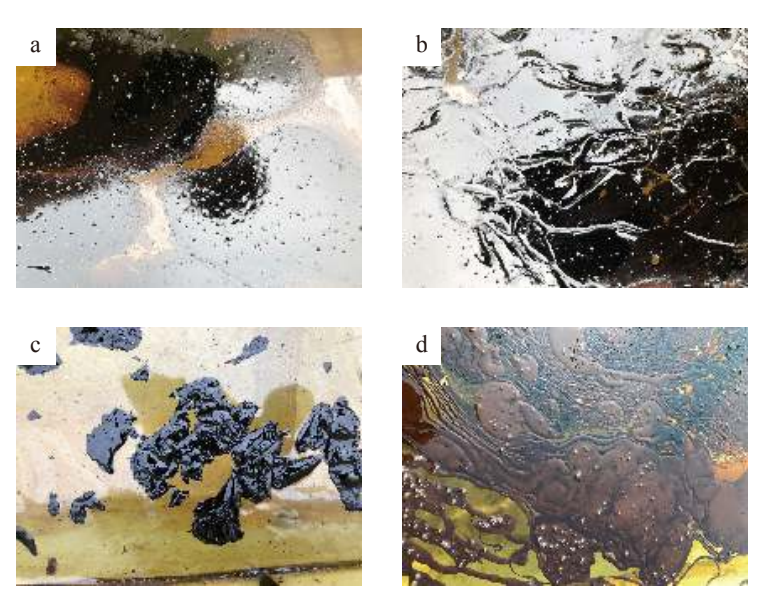

Fig. 7. Emulsified oil film during experiment: the oil film surface has a much greater roughness than the calm water surface, which leads to an increase in the backscatter of the oil film surface and $\sigma_{\text {oil }}^{0}>\sigma_{\text {water }}^{0}$. a. Surface of oil film after resting overnight, $\mathrm{b}$. stacked emulsified mixture after stirring, c. distribution of oil blocks after stirring, d. unmixed emulsified oil film.

id with a loose and porous surface (Fingas and Fieldhouse, 2003, 2004; Fingas, 1995). After stirring, the emulsion stacked into fragments that were distributed over the water surface (Figs $7 \mathrm{~b}, \mathrm{c}$ ). At this time, the roughness of the oil film surface had a higher roughness than the calm water surface, which led to an increase in the backscatter of the oil film, such that $\sigma_{\text {oil }}^{0}>\sigma_{\text {water }}^{0}$. This conclusion appears to be inconsistent with the classical theory that an oil spill reduces radar backscatter. In fact, the oil spill reduces the radar backscatter by inhibiting capillary-gravity waves on a dynamic sea surface. However, the experiments in this study were carried out in an ideal environment with a low wind speed and no waves, such that the water surface in the tank was calm, and capillary or gravity waves were absent. Therefore, under the same incident angle, the radar backscatter mainly depended on the change in the surface roughness. The type A oil used in the experiment had an asphalt content below $3 \%$ and was thus a crude oil prone to emulsification. During the experiment, the sample was artificially stirred and allowed to rest after each incremental oil addition to ensure complete emulsification. The density of the emulsion was less than that of the seawater. The emulsion floated on the surface of the seawater and increased the surface roughness and backscatter (Fig. 7). Therefore, the emulsification of crude oil significantly changed the film surface roughness and increased the backscatter.

\subsection{Effect of oil film emulsification on backscatter}

In this section, the effect of the emulsification process of the oil film on the backscatter is investigated by analyzing the experimental results for type $\mathrm{B}$ and $\mathrm{C}$ crude oils with different moisture constants. The experimental results in Figs 8 and 9 show that $\sigma_{\mathrm{VV}}^{0}$, $\sigma_{\mathrm{HV} / \mathrm{VH}}^{0}$ and $\sigma_{\mathrm{HH}}^{0}$ decrease as the incident angle increases. The rate of decrease becomes smaller as the incident angle increases. As shown in Fig. 8, for the type B oil, $\sigma^{0}$ for the different polarization modes increases with the moisture constant: $\sigma_{w_{c}=20 \%}^{0}>$ $\sigma_{w_{c}=10 \%}^{0}>\sigma_{w_{c}=0 \%}^{0}\left(W_{C}\right.$ represents the moisture constant). As B$30 \%$ (type $\mathrm{B}$ oil with a moisture constant of $30 \%$ ) was mainly distributed between the incident angles of $25^{\circ}$ and $50^{\circ}$, the abovementioned trend only applies to $\sigma_{w_{c}=30 \%}^{0}$ for incident angles between $25^{\circ}$ and $50^{\circ}$.
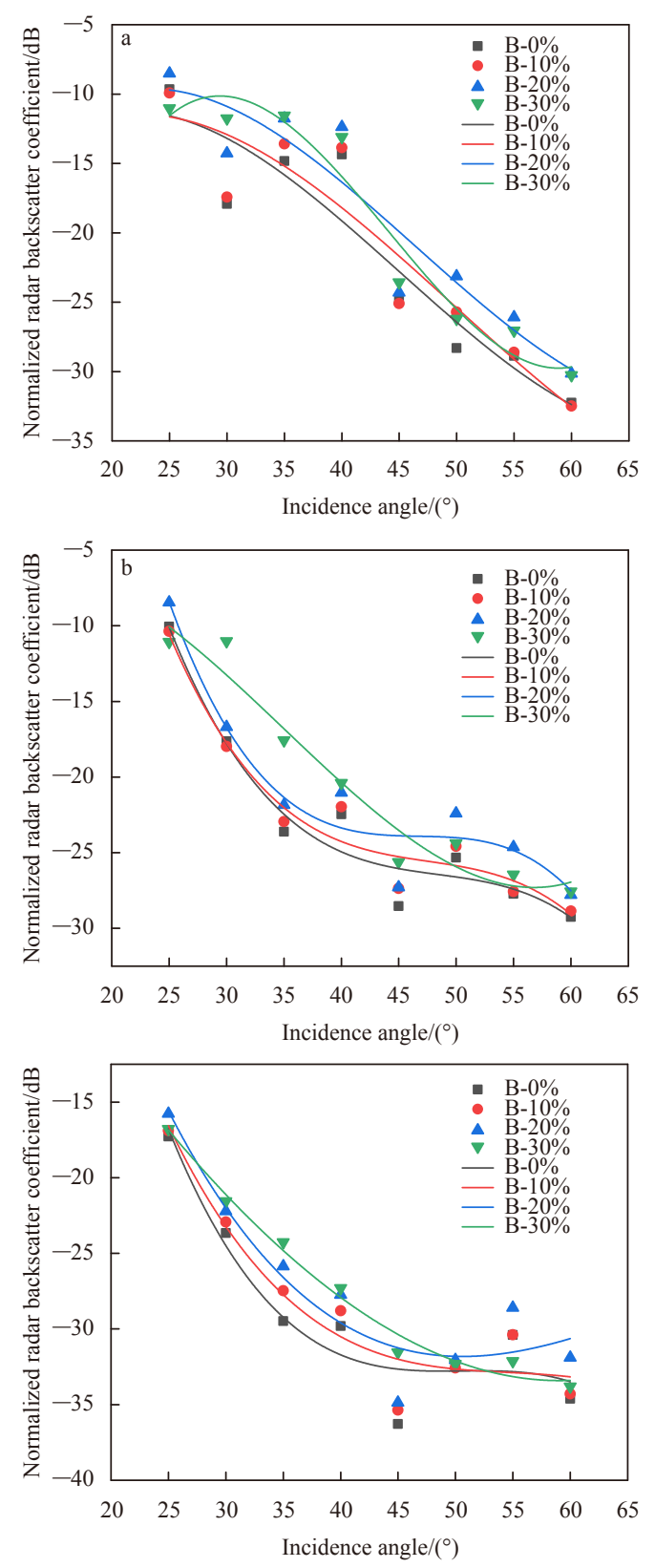

Fig. 8. Observed backscatter from surface of type B oil with $0 \%$, $10 \%, 20 \%$, and $30 \%$ moisture constants: $\sigma_{\mathrm{VV}}^{0}(\mathrm{a}), \sigma_{\mathrm{HH}}^{0}(\mathrm{~b})$, and $\sigma_{\mathrm{HV} / \mathrm{VH}}^{0}(\mathrm{c})$. Backscatter trend lines are cubic fits, and colored points are measured values.

The type B oil spread evenly to form an oil film (Fig. 10). The surface roughness of the oil film with different moisture constants was relatively consistent. But the value of $\sigma^{0}$ increased with the moisture constant of the oil film. This result can be explained using the semi-empirical model (SEM), which derived at the University of Michigan (Richards, 2009). The backscatter of the polarization and cross-polarization can be expressed as follows:

$$
\sigma_{\mathrm{VV}}^{0}(\theta)=\frac{g \cos ^{3} \theta}{\sqrt{p}}\left\{\left|\rho_{\mathrm{V}}\right|^{2}+\left|\rho_{\mathrm{H}}\right|^{2}\right\}
$$

where 

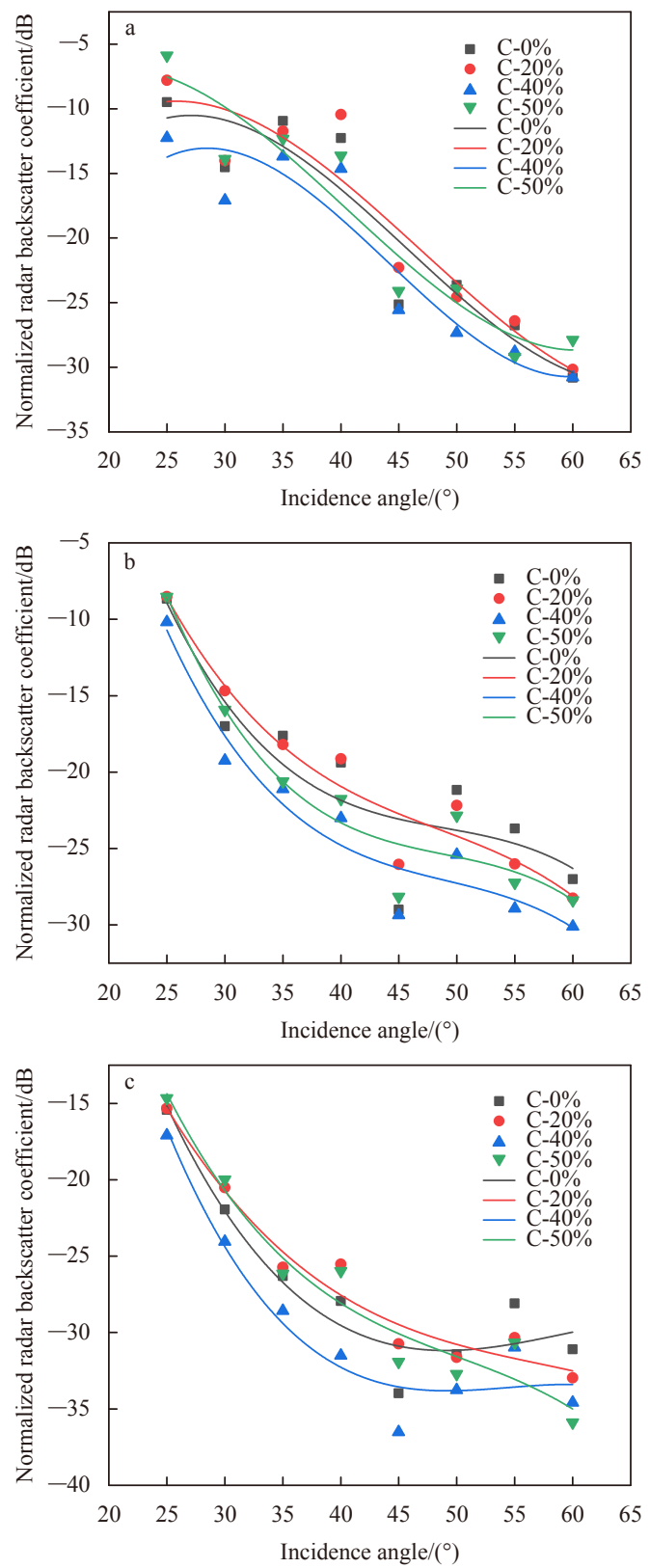

Fig. 9. Observed backscatter from surface of type $\mathrm{C}$ oil with $0 \%$, $20 \%, 40 \%$, and $50 \%$ moisture constants: $\sigma_{\mathrm{VV}}^{0}(\mathrm{a}), \sigma_{\mathrm{HH}}^{0}(\mathrm{~b})$, and $\sigma_{\mathrm{HV} / \mathrm{VH}}^{0}(\mathrm{c})$. Backscatter trend lines are cubic fits, and colored points are measured values.

$$
g=0.7\left\{1-\exp \left[-0.65(k s)^{1.8}\right]\right\}
$$

Further,

$$
\begin{gathered}
\sigma_{\mathrm{HH}}^{0}(\theta)=p \sigma_{\mathrm{VV}}^{0}(\theta), \\
\sigma_{\mathrm{HV} / \mathrm{VH}}^{0}(\theta)=q \sigma_{\mathrm{VV}}^{0}(\theta),
\end{gathered}
$$

with

$$
p=\left[1-\left(\frac{2 \theta}{\pi}\right)^{\frac{0.33}{|\rho(0)|^{2}}} \exp (-k s)\right]^{2}
$$

$$
\begin{gathered}
q=0.23|\rho(0)|[1-\exp (-k s)], \\
\rho(0)=\frac{1-\sqrt{\varepsilon_{r}}}{1+\sqrt{\varepsilon_{r}}}
\end{gathered}
$$

where $\theta$ is the incidence angle, $k=2 \pi / \lambda$ is the wave number of the radar, $\boldsymbol{s}$ is the rms variation in the surface height, $\varepsilon_{r}$ is the relative dielectric constant, and $\rho(0)$ is the Fresnel reflection coefficient at vertical incidence. The polarization dependent reflection coefficients, $\rho_{\mathrm{H}}$ and $\rho_{\mathrm{V}}$, are defined as follows:

$$
\begin{gathered}
\rho_{\mathrm{H}}=\frac{\cos \theta-\sqrt{\varepsilon_{r}-\sin ^{2} \theta}}{\cos \theta+\sqrt{\varepsilon_{r}-\sin ^{2} \theta}}, \\
\rho_{\mathrm{V}}=\frac{-\varepsilon_{r} \cos \theta+\sqrt{\varepsilon_{r}-\sin ^{2} \theta}}{\varepsilon_{r} \cos \theta+\sqrt{\varepsilon_{r}-\sin ^{2} \theta}} .
\end{gathered}
$$

Equations (1)-(11) were used to simulate the change in $\sigma^{0}$ with the dielectric constant $\varepsilon_{r}$. The simulation results in Fig. 11 show a linear positive correlation between $\sigma^{0}$ and $\varepsilon_{r}$. The measured dielectric constants show that the relative dielectric constant of the oil film is monotonically positively correlated with the moisture constant (Table 6). These results prove that the backscatter $\sigma^{0}$ increased with the moisture constant of the oil film.
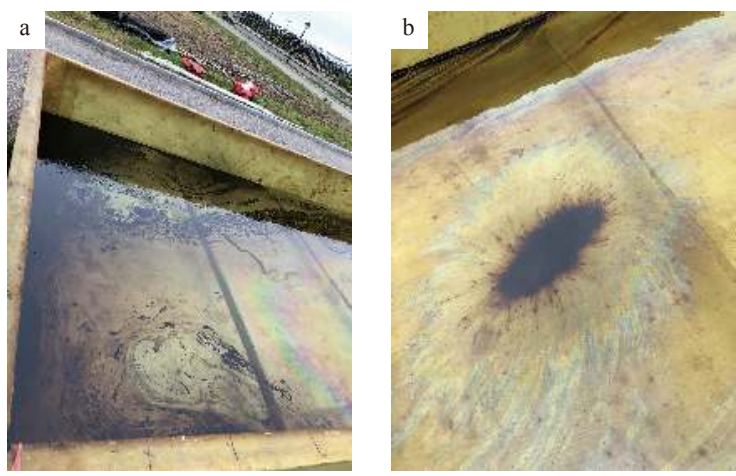

Fig. 10. Distribution of type B oil film during the experiment: the oil diffuses easily and evenly distributes into a film. a. Distribution of oil film and b. diffusion of oil blocks.

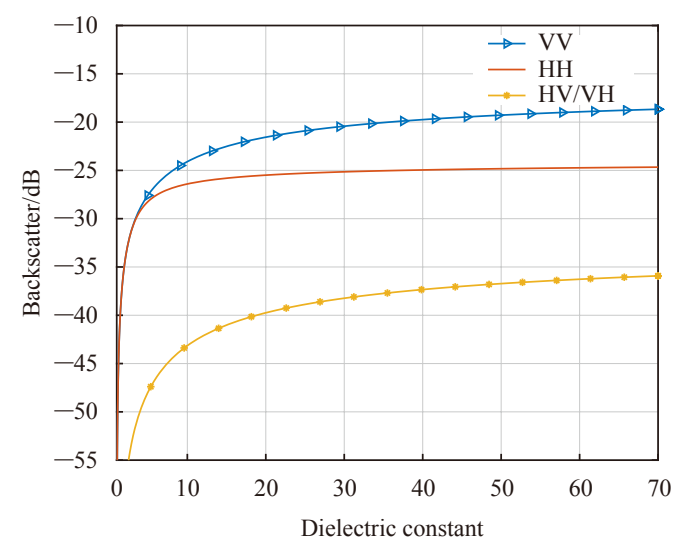

Fig. 11. Changes in backscatter and dielectric constant simulated by the semi-empirical model. Different lines represent different polarization modes. 
For the type $\mathrm{C}$ oil, no significant relationship was obtained between the backscatter and the moisture constant. Under the same incident angle, the maximum backscatter was $\sigma_{w_{\mathrm{c}}=20 \%}^{0}$ (the backscatter of the oil film with a $20 \%$ moisture constant) for each polarization mode, whereas the corresponding minimum backscatter was $\sigma_{w_{\mathrm{c}}=40 \%}^{0}$. The video data demonstrated that this result was caused by inconsistent distributions of the oil film for different moisture constants (Fig. 12). The hydrophilic components were removed from the processed type $\mathrm{C}$ oil that was used in the experiment; thus, the oil films with $0 \%, 20 \%$, and $30 \%$ moisture constants did not spread easily, and most of the oil stacked into oil blocks. The largest distribution density of oil blocks was obtained for a $20 \%$ moisture constant (Fig. 12b). At a moisture constant of $40 \%$, the type $\mathrm{C}$ oil rapidly spread across the tank into a thin film (Fig. 12c). The accumulation of the oil film on the water surface resulted in an oil film roughness that was significantly different from that of the surrounding water. At a $20 \%$ moisture constant, the extent of the surface stacking was the greatest, the surface roughness was the largest, and the corresponding backscatter was high. Conversely, at a $40 \%$ moisture constant, the surface was the smoothest with minimal roughness, and the corresponding backscatter was the lowest.

In summary, the results show that under the conditions of a low wind speed and no waves, the emulsification modulated the radar backscatter through changes in the surface roughness and the dielectric constant of the oil film. A comparison of the experimental results of the type $\mathrm{B}$ and $\mathrm{C}$ oils shows that the backscatter results were dominated by the surface roughness.

\subsection{Analysis of backscatter differences among different types of oil}

In this section, the differences in the oil surface backscatter between the type $\mathrm{B}$ and $\mathrm{C}$ oils in the emulsified and crude states are analyzed. When the oil film was not emulsified, the backscatter of the type $\mathrm{C}$ oil was greater than that of the type $\mathrm{B}$ oil under the same polarization mode (Fig. 13a). At moderate incident angles $\left(25^{\circ}-35^{\circ}\right)$, this difference in the backscatter increased with the incident angle. The average differences were $2.19 \mathrm{~dB}, 2.63 \mathrm{~dB}$, and $2.21 \mathrm{~dB}$ for the polarization modes of $\mathrm{VV}, \mathrm{HH}$, and $\mathrm{HV} / \mathrm{VH}$, respectively.

Figure 13b shows the changes in the backscatter with the incident angle for the type B and type C oils with a $20 \%$ moisture
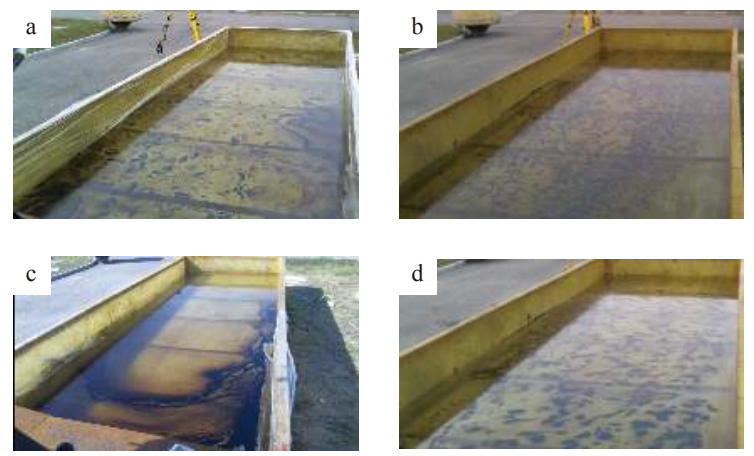

Fig. 12. Distribution of the type $C$ oil film with different moisture constants during the experiment: $W_{\mathrm{c}}=0 \%(\mathrm{a}) ; W_{\mathrm{c}}=20 \%$ (b); $W_{\mathrm{c}}=30 \%$ (c); and $W_{\mathrm{c}}=50 \%$ (d). The oil with $0 \%, 20 \%$, and $30 \%$ moisture constants did not spread easily, and most of the oil stacked into oil blocks. The extent of surface stacking was largest for oil with a $20 \%$ moisture constant, and the surface was the smoothest for oil with a $40 \%$ moisture content.
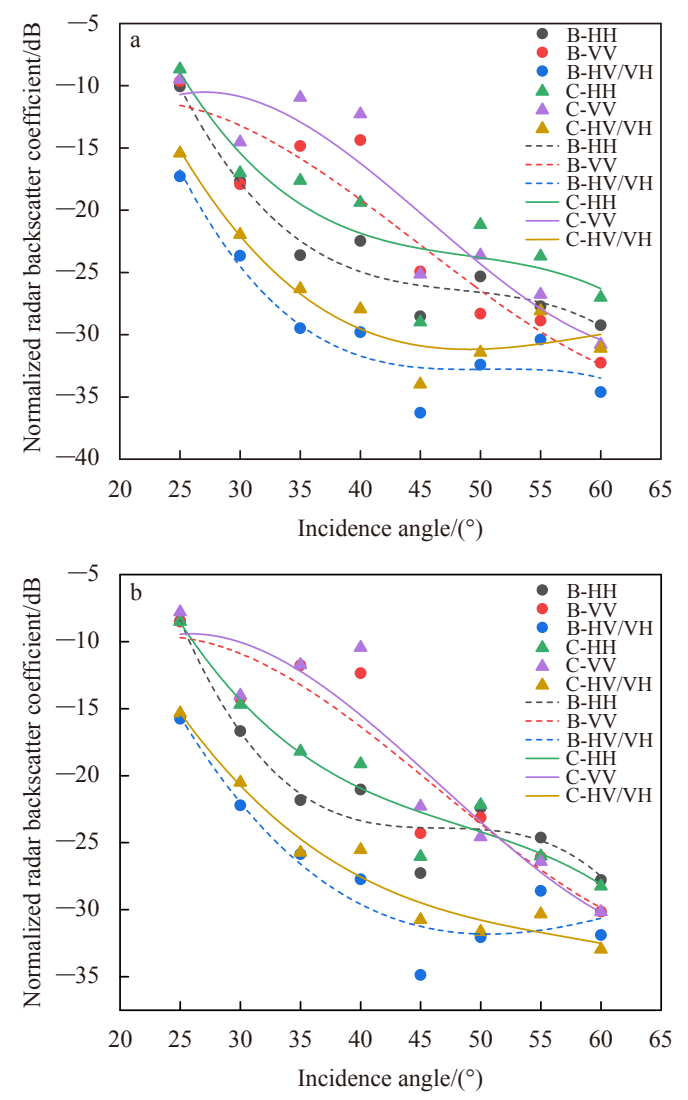

Fig. 13. Changes in $\sigma_{\mathrm{VV}}^{0}, \sigma_{\mathrm{HV} / \mathrm{VH}}^{0}$ and $\sigma_{\mathrm{HH}}^{0}$ with incident angle in type B and C and oil films: non-emulsified state (a) and emulsified state with $20 \%$ moisture constant (b). Backscatter trend lines are cubic fits, and colored points are measured values.

constant in the emulsified state. Within the incident angle range of $25^{\circ}-50^{\circ}$, the backscatter of the type $\mathrm{C}$ oil film surface was greater than that of the type B oil under the same polarization mode. However, this difference was smaller than for the non-emulsified state, and the corresponding values were $0.98 \mathrm{~dB}, 1.49 \mathrm{~dB}$, and $1.5 \mathrm{~dB}$. The backscatter of the type $\mathrm{B}$ oil film was greater than that of the type $\mathrm{C}$ oil between the incident angles of $50^{\circ}-60^{\circ}$. Comparing Figs $12 \mathrm{~b}$ and 14 shows that this phenomenon occurred because the type $B$ oil film had a higher distribution density than the type $\mathrm{C}$ oil film in this incident angle range.

The difference in the backscatter of the two types of oil was caused by the difference in the oil compositions. The type B oil was an unprocessed crude oil from an oilfield, whereas the type $\mathrm{C}$ oil was a dehydrated and purified industrial crude oil. The videos

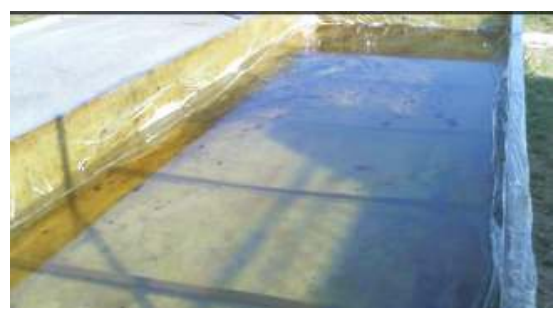

Fig. 14. Distribution of emulsified type B oil film with a $20 \%$ moisture constant: a uniform thin film formed under incident angles of $25^{\circ}-50^{\circ}$ but dispersed at incident angles of $50^{\circ}-60^{\circ}$. 
and photographs of the oil film diffusion showed that the type B oil had a high diffusion rate in water and rapidly covered a large area of the tank (Figs 11 and 12). The removal of the hydrophilic components of the type $\mathrm{C}$ oil resulted in a slow diffusion rate, such that this oil was difficult to disperse and easily accumulated on the water surface. Therefore, the type B oil had a lower surface roughness than the type $C$ oil in the same emulsification state and a smaller backscatter.

Notably, the difference in the backscatter between the different types of oil films decreased after emulsification. Using Figs 8 and 9 , this decrease was attributed to the higher increase in the backscatter for the type B oil after emulsification than for the type C oil.

\section{Conclusions}

Outdoor tank experiments were conducted to investigate whether an emulsification-induced state change affects the microwave scattering characteristics of an oil film or the detection accuracy of an oil spill. A C-band fully-polarimetric microwave scatterometer was used to observe the backscatter of the oil film surfaces of three different types of crude oil (A, B and C) during the emulsification process. Under the conditions of a low wind speed and no waves, the difference in the backscatter between the emulsified oil film and the surface of the calm water and the influence of the emulsification process on the backscatter were analyzed in detail. The differences in the backscatter between the different types of oil were also analyzed.

The experimental results showed that the water-in-oil emulsion of crude oil exhibited characteristics between those of a liquid and a solid (Fig. 8) and increased the surface roughness. Under the VV, $\mathrm{HH}$ and $\mathrm{HV} / \mathrm{VH}$ polarization modes, the backscatter of the emulsified oil film was greater than that of calm water by $71.15 \%, 78.21 \%$, and $64.1 \%$, respectively (Fig. 7 ). The preliminary conclusion is that crude oil emulsification can change the surface roughness.

The changes in the backscatter $\sigma^{0}$ and the dielectric constant $\varepsilon_{r}$ were simulated using SEM. The results showed that there was a linear positive correlation between $\sigma^{0}$ and $\varepsilon_{r}$ (Fig. 11). The vector network analyzer data showed that the dielectric constant of the oil film was positively correlated with the moisture constant of the oil (Table 6). The experimental results were in agreement with the simulation results. The backscatter increased with the moisture constant of the oil film (Fig. 9). It was concluded that the emulsification modulated the radar backscatter through changes in the dielectric constant and the surface roughness. Comparing the experimental results of the type B and C oils showed that the backscatter was dominated by the surface roughness.

The differences in the backscatter between the type B and C crude oils were compared for the emulsified and non-emulsified states. The mean differences in the backscatter for the non-emulsified state were $2.19 \mathrm{~dB}, 2.63 \mathrm{~dB}$, and $2.21 \mathrm{~dB}$ under the $\mathrm{VV}, \mathrm{HH}$, and HV/VH polarization modes, respectively (Fig. 13a). The corresponding differences in the emulsified state with a $20 \%$ moisture constant were much smaller: $0.98 \mathrm{~dB}, 1.49 \mathrm{~dB}$, and $1.5 \mathrm{~dB}$ (Fig. 13b). The differences in the oil compositions and oil film properties may have affected the surface roughness of the oil films to some extent.

The experiments were carried out in an outdoor water tank under a low-wind and no-wave environment. The experimental results showed that the emulsification process had a significant impact on the microwave scattering characteristics of the oil films. This study serves as a reference for the detection of oil spills and the improvement in the oil spill detection accuracy of a C-band microwave sensor under a calm sea state. Future research should explore the effect of oil spill emulsification on the microwave scattering characteristics of an oil film surface in an actual marine environment. Different band sensors are also needed to evaluate the responses of different bands to the emulsification of an oil spill.

\section{Acknowledgements}

We thank the Muping Coastal Environment Research Station of the Chinese Academy of Science for allowing the experiment to be performed and providing ground truth data.

\section{References}

Alpers W, Hühnerfuss H. 1988. Radar signatures of oil films floating on the sea surface and the Marangoni effect. Journal of Geophysical Research, 93(C4): 3642-3648, doi: 10.1029/JC093iC 04p03642

Angelliaume S, Boisot O, Guérin C A. 2018. Dual-polarized L-band SAR imagery for temporal monitoring of marine oil slick concentration. Remote Sensing, 10(7): 1012, doi: 10.3390/ rs10071012

Baldi C A. 2014. The design, validation, and analysis of surface-based S-band and C-band polarimetric scatterometers [dissertation]. United States: University of Massachusetts Amherst

Brekke C, Solberg A H S. 2005. Oil spill detection by satellite remote sensing. Remote Sensing of Environment, 95(1): 1-13, doi: 10.1016/j.rse.2004.11.015

Chehresa S, Amirkhani A, Rezairad G A, et al. 2016. Optimum features selection for oil spill detection in SAR image. Journal of the Indian Society of Remote Sensing, 44(5): 775-787, doi: 10.1007/s12524-016-0553-x

Cai Yang, Zou Yarong, Liang Chao, et al. 2016. Research on polarization of oil spill and detection. Acta Oceanologica Sinica, 35(3): 84-89, doi: 10.1007/s13131-015-0817-x

Del Frate F, Petrocchi A, Lichtenegger J, et al. 2000. Neural networks for oil spill detection using ERS-SAR data. IEEE Transactions on Geoscience and Remote Sensing, 38(5): 2282-2287, doi: $10.1109 / 36.868885$

De Loor G P, Van Hulten H W B. 1978. Microwave measurements over the North Sea. Boundary-Layer Meteorology, 13(1-4): 119-131, doi: 10.1007/BF00913866

Fingas M. 1995. Water-in-oil emulsion formation: A review of physics and mathematical modelling. Spill Science \& Technology Bulletin, 2(1): 55-59

Fingas M F, Brown C E. 1997. Review of oil spill remote sensing. Spill Science \& Technology Bulletin, 4(4): 199-208

Fingas M, Brown C. 2014. Review of oil spill remote sensing. Marine Pollution Bulletin, 83(1): 9-23, doi: 10.1016/j.marpolbul. 2014.03.059

Fingas M, Fieldhouse B. 2003. Studies of the formation process of water-in-oil emulsions. Marine Pollution Bulletin, 47(9-12): 369-396, doi: 10.1016/S0025-326X(03)00212-1

Fingas M, Fieldhouse B. 2004. Formation of water-in-oil emulsions and application to oil spill modelling. Journal of Hazardous Materials, 107(1-2): 37-50, doi: 10.1016/j.jhazmat.2003.11.008

Gade M, Alpers W, Hühnerfuss H, et al. 1998. Wind wave tank measurements of wave damping and radar cross sections in the presence of monomolecular surface films. Journal of Geophysical Research: Oceans, 103(C2): 3167-3178, doi: 10.1029/ 97JC01578

Gemme L, Dellepiane S G. 2018. An automatic data-driven method for SAR image segmentation in sea surface analysis. IEEE Transactions on Geoscience and Remote Sensing, 56(5): 2633-2646

Girard-Ardhuin F, Mercier G, Collard F, et al. 2005. Operational oilslick characterization by SAR imagery and synergistic data. IEEE Journal of Oceanic Engineering, 30(3): 487-495, doi: 10.1109/JOE.2005.857526 
Guo Jie, Meng Junmin, He Yijun. 2016. Scattering model research based on two-dimensional laser observation of spilled oil and emulsification processes. Marine Sciences (in Chinese), 40(2): 159-164

Khan B A, Akhtar N, Khan H M S, et al. 2011. Basics of pharmaceutical emulsions: A review. African Journal of Pharmacy and Pharmacology, 5(25): 2715-2725

Leifer I, Lehr W J, Simecek-Beatty D, et al. 2012. State of the art satellite and airborne marine oil spill remote sensing: Application to the BP Deepwater Horizon oil spill. Remote Sensing of Environment, 124: 185-209, doi: 10.1016/j.rse.2012.03.024

Migliaccio M, Nunziata F, Gambardella A. 2009. On the co-polarized phase difference for oil spill observation. International Journal of Remote Sensing, 30(6): 1587-602, doi: 10.1080/0143116 0802520741

Minchew B, Jones C E, Holt B. 2012. Polarimetric analysis of backscatter from the Deepwater Horizon oil spill using L-band synthetic aperture radar. IEEE Transactions on Geoscience and Remote Sensing, 50(10): 3812-3830, doi: 10.1109/TGRS. 2012.2185804

Pang Aimei, Sun Yuanfu. 2003. Laboratory measurement and analysis of microwave radiation characteristics of oil slick on water surface. Coastal Engineering (in Chinese), 22(4): 36-41

Richards J A. 2009. Remote Sensing with Imaging Radar. Berlin, Heidelberg: Springer-Verlag

Skrunes S, Brekke C, Eltoft T. 2014. Characterization of marine surface slicks by Radarsat-2 multipolarization features. IEEE Transactions on Geoscience and Remote Sensing, 52(9): 5302-5319, doi: 10.1109/TGRS.2013.2287916

Skrunes S, Brekke C, Jones C E, et al. 2016. A multisensor comparison of experimental oil spills in polarimetric SAR for high wind conditions. IEEE Journal of Selected Topics in Applied Earth Observations and Remote Sensing, 9(11): 4948-4961, doi: 10.1109/JSTARS.2016.2565063

Solberg A H S, Dokken S T, Solberg R. 2003. Automatic detection of oil spills in Envisat, Radarsat and ERS SAR images. International Geoscience and Remote Sensing Symposium, (4): 2747-2749, doi: doi: 10.1109/igarss.2003.1294572

Thingstad T, Pengerud B. 1983. The formation of "chocolate mousse" from Statfjord crude oil and seawater. Marine Pollution Bulletin, 14(6): 214-216, doi: 10.1016/0025-326X(83)90254-0

Topouzelis K, Karathanassi V, Pavlakis P, et al. 2007. Detection and discrimination between oil spills and look-alike phenomena through neural networks. ISPRS Journal of Photogrammetry and Remote Sensing, 62(4): 264-270, doi: 10.1016/j.isprsjprs. 2007.05.003

Topouzelis K, Karathanassi V, Pavlakis P, et al. 2008. Dark formation detection using neural networks. International Journal of Remote Sensing, 29(16): 4705-4720, doi: 10.1080/0143116 0801891770

Ulaby F T, Moore R K, Fung A K. 1986. Microwave Remote Sensing: Active and Passive. Vol III: From Theory to Applications. Reading, MA: Artech House, Inc

Wismann V, Gade M, Alpers W, et al. 1998. Radar signatures of marine mineral oil spills measured by an airborne multi-frequency radar. International Journal of Remote Sensing, 19(18): 3607-3623, doi: 10.1080/014311698213849

Yang Yuezhong, Lu Guixin, Zhong Qiying, et al. 1993. A study on measuring the thickness of oil film on the sea by airborne remote sensing. Remote Sensing of Environment China (in Chinese), 8(3): 222-231

Zou Yarong, Shi Lijian, Zhang Shengli, et al. 2016. Oil spill detection by a support vector machine based on polarization decomposition characteristics. Acta Oceanologica Sinica, 35(9): 86-90, doi: 10.1007/s13131-016-0935-5

Zheng Honglei, Zhang Yanmin, Wang Yunhua, et al. 2017. The polarimetric features of oil spills in full polarimetric synthetic aperture radar images. Acta Oceanologica Sinica, 36(5): 105-114, doi: 10.1007/s13131-017-1065-4 


\section{Appendix:}

The experiment was carried out in two stages. In the second stage, three different types of crude oil were used, and the scatterometer measurements of each oil sample were carried out in the same tank. At the end of each oil sample measurement, the tank was cleaned. Figure Al shows the two steps of the cleaning process. The thick oil film is first cleaned using a deoiling drum. Then, the thin oil film is cleaned using a suction felt. To ensure that the preliminary experiment does not affect the measurement results of subsequent oil samples, the water surface after each oil removal is measured by a scatterometer, and the results are used to verify the removal. In this paper, the backscattering data of water surface and pure sea water surface before oil removal are analyzed. Figure A2 shows that this difference under different polarization modes is small, where the average difference for the $\mathrm{VV}, \mathrm{HH}$ and $\mathrm{HV} / \mathrm{VH}$ polarization modes are $0.43 \mathrm{~dB}, 0.45 \mathrm{~dB}$ and $0.46 \mathrm{~dB}$, respectively. These differences are caused by not only residual oil stains but also other factors, such as local gusts. In summary, the cleaning process in the experiment is ideal, and the measurement of each oil sample is not affected by the residual oil stain of the previous sample.
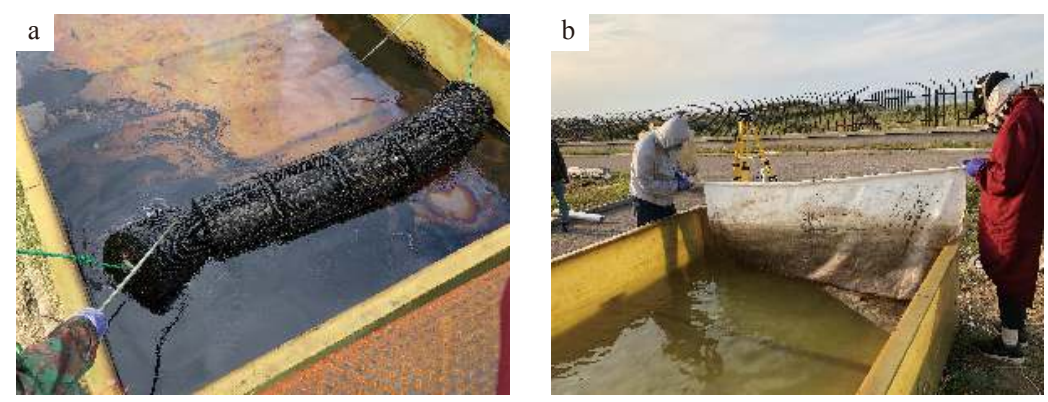

Fig. A1. Two-step oil removal process in the second experimental stage: first, a thick oil film layer is removed using absorbing rollers (a) and then, a thin oil film is removed using absorbent linoleum (b).
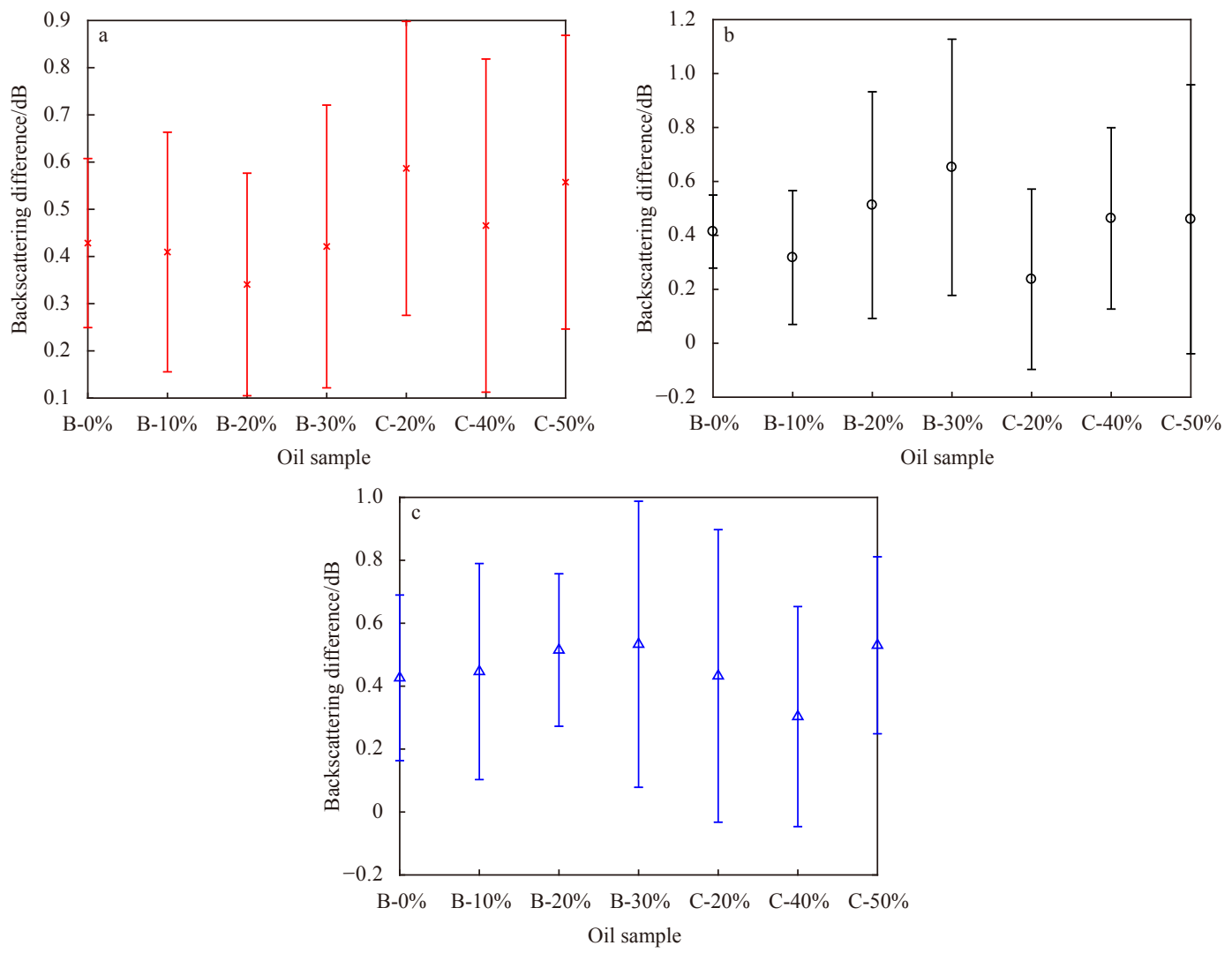

Fig. A2. Mean and standard deviation of backscattering difference between seawater surface and pure seawater surface after oil removal: $\mathrm{VV}(\mathrm{a}), \mathrm{HH}(\mathrm{b})$, and $\mathrm{HV} / \mathrm{VH}$ (c). The $\mathrm{C}-0 \%$ oil sample is measured first in the experiment. 